\title{
Explanation of the Ontology Value of Olympics Opening Ceremonies
}

\author{
Li Feng-mei \\ Sport Science College, Fujian Normal University, Fujian Province, China \\ Lfm3911@126.com
}

\begin{abstract}
In order to further know the ontology value of the Olympics opening ceremonies, by the methods of literature and logic, its cultural implication is also analyzed on the basis of analyzing its influential factors, namely, the full combination of sadness sport and happiness culture, the indirect reflection of material wealth and political power and the external expression of the identity of nationality and the peaceful volution of culture; and eventually several suggestions are put forward purposefully so as to promote its fluent and healthy development. value

Index Terms - Olympics opening ceremonies, influential factors,
\end{abstract}

\section{Introduction}

The Olympics opening ceremony is the important carrier of explaining the Olympic spirit and showing the cultural style of nation, and also plays an important role of advocating and spreading the universal value. "Because of the different cultural history, political economy, scientific culture and customs, all previous ceremonies are different".[1] Take the opening ceremonies of Beijing Olympics and London Olympics for example, the former emphasizes "joy" and the latter is "celebration" in the atmosphere; the former highlights "culture" and the latter is "humanity" in the topics; the former produces the visual impulse and the latter is the spiritual shock in the design. It also reflects the two different thinking modes: Chinese are good at abstract and British are specific; Chinese pay attention to the form and British attach importance to the content. So the endowed value and function of Olympics are finished in such a way. However, for the interaction and continual competition the special culture is being exploited and utilized excessively by some groups, which weakens and distorts the educational value of Olympic Movement and its holy meaning, and even endangers the Olympic spirit. Therefore it is very necessary and important to know and discuss further the factors and value of the ceremonies so as to help their healthy development.

\section{Analysis of influential factors}

\section{A. The International Environment}

Through more than one hundred-year-old development of the Olympics the international political situations and the economical development have made a great change, while the opening ceremonies named the flower of the Olympics have been profoundly imprinted the political color. From the first $19^{\text {th }}$ century when they confronted some social hindrances to the present age when they are entangled by sorts of groups, from the enveloped shadow of war and the economical crisis and the significant influence of racism to the kidnapping of political forces, all demonstrate the development of the Olympics is closely linked with the international environment, while the change of ceremonies is related to the international political situations and the economical level. In the light of the background and the history of the Olympics the development of ceremonies will be restrained directly and indirectly by the international environment.

\section{B. The Technology}

The technology has not only changed the modes of life and production but also influenced the development of Olympics opening ceremonies. The built stage and the lightning design and the traversing performances both on and off the scene, coupled with the glaring fireworks, have indicated that the technology is irreplaceable for the modern Olympics. "It is the technology that boosts the delivery tools of culture, especially the popularization of TV, which breeds the sports market and makes the easy ways host countries characterize their styles."[2] Judging from the whole effects of the successive ceremonies, the great miracles and splendid moment have created by the perfect cooperation of artificial intelligence and the miraculous display of soundphotoelectricity or the high-tech methods.

\section{The Native Culture}

The Olympics opening ceremony is the important stage of promoting the Olympic culture and spirit, the special medium of propagandizing the local culture of host countries. By the traits and ways of the recent ceremonies, they have been innovated and surpassed on the basis of the principle of inheritance, aiming at featuring the outstanding tradition of history and the great achievements of modern civilization about host countries. Their traits of the traditional culture, people's affinity and the cultural attraction have displayed in the artistic performances. In addition, it has almost become the main measurement of the result of ceremonies directly or indirectly.

\section{The Level of Sport}

The level of sport is measured in two aspects, namely, the development of sports technology and people's cognition of sport. Both are interplaying and give an impact on the ceremonies in a dominant or recessive, direct or indirect way. To some extent, they not only determine the national policy orienation and the social position about the development of sport, but also show sports function in daily life. Furthermore, 
the national ideology partly influences the mode and level of sport. So it is this influence that renders the performing form and the scene design and the whole atmosphere distinct .

\section{E. The Events Experience}

The people's attitude and concept about holding the Olympics is different between the first time and the second one. Except for other events experiences, the direct experiences of holding the Olympics make an influence on the organization and administration, and the contents and styles of artistic performances. After all, for countries with the experiences of major events or the Olympics, the accumulative experiences and lessons can help save the expenditure and promote people's confidence and innovation capability, especially for persons serving for events. Compared with the experienced America and British, the opening ceremony of 2008 Beijing Olympics includes the dream of the five circles and the Tai Chi performance but has been considered "the whole show is isolated from the history of sport".[3] In the author's opinion, it just relates to people's cognition and the major events experiences.

\section{Allegorical Interpretation of Olympics Opening Ceremonies}

As the larger scale of organization and the spread influences, the Olympics has been a chip for various forces and groups, and "the concept of the Olympics has substantially exceeded the Olympics itself." [4] From the overall effects of recent successive ceremonies, its intrinsic significance and educational value have been covered by the overt orientation of politics and economy; it is a linguistic game used by some people or groups, rather than the special culture of host countries and the Olympic spirit which are just the surface or the meaning interpreted deliberately.

\section{A. The Opening Ceremony is the high Combination of Sadness Sport and Happiness Culture}

The modern opening ceremonies produce a special atmosphere of festival and joyful culture by the colorful stage design, the solemn atmosphere, the large-scale participation and the reappearance of the traditional culture. A formal and celebrating feeling of the Olympic festival is embodied through the invited guests' and athletes' dressing styles and the spectators' spirituality on the spot. When we are intoxicated in the grand and sacred scene, few persons compare it with the following cruel competition and athletes' peculiar experiences. We have to admit a fact that it is difficult to protect and persist in the Olympic principles and the ideal concept of development for the influences of politics and economy and culture, though it strives for the harmonious development of mankind in the way of the competitive sport. It has been practicing the succession of swifter higher and stronger, but it ends in the result of defeating others and being defeated. And then the real humanistic care about some countries and athletes has been neglected and lost. Concerning opening ceremonies "art replaces religion and the aesthetic creates the lofty",[5] and meanwhile the sad sport is reflected by the happy culture.
In a way it is their both high combination.

\section{B. The Opening Ceremony is the Indirect Reflection of Material Wealth and Political Power}

The Olympics derives from the industrial civilization and then are characteristic of the industrialization, so both applying conditions and the organizing mode must rely on the materials. Its planning and implementation are not an exception, and even it is the complete reappearance of art and culture on the basis of materials. So it reflects the extreme dependence of the capital and the wealth of host countries or cities. In the meanwhile the Olympics and their ceremonies are imprinted the fierce political color under the game between the change of the international environment and countries, and even an indirect method of the checks and balances about the different ideology or demonstrating the superiority of the different systems. In the Beijing Olympics "we have not just gained the glorious achievement of the first place in the number of gold metals and launched the Shenzhou VII spacecraft into space soon after the extinguishing Olympic flame."[6] We should not read the Olympics in such a way but similar words full of people's feelings are here and there. On this position the ceremonies have become the special wealth and the political capital for some countries.

\section{The Opening Ceremony is the External Expression of the Identity of Nationality and the Peaceful Evolution of Culture}

Many host countries make great endeavors to gain the identity of nationality by elaborately planning and implementing the ceremonies, especially for those developing ones being bullied and squeezed, it indeed plays an irreplaceable role. Someone declares that "it is the grand opening ceremony that fulfills Chinese ambitions."[7] In addition, the influence and attraction of host countries culture are increased through showing and propagating the excellent culture and the universal value in the artistic performances. Many countries are eager to attract the worldwide attentions by hosting the Olympics so as to advertise own culture and policies and the comprehensive national power and to promote the international influence, and then to publicize own ideology and to enhance the prestige and position in the world. Few countries are not an exception in this point. In the light of the cultural psychology and value orientation, the opening ceremonies have evolved as a special rite of the identity of nationality and culture.

\section{Considerations about the Development of Opening Ceremonies}

The opening ceremonies are endowed multiple meanings and have almost deviated from the original pureness and ideal, but we hope it will still play a positive role of the progress of mankind and society. Even though its religious color is regularly fading we should believe its unique value as the faith and totem will encourage people to live together peacefully and healthily. 


\section{A. Controlling and Enriching Contents of Artistic Performances}

All successive artistic performances have changed from emphasizing the rites originally to the demonstration subsequently, from seeking the form solemnly to creating the atmosphere relaxedly. It coincides with the logic of the Olympics: the lighter religiousness and the stronger artistry, the lighter rituality and the stronger secularity. Because many cultural elements and symbols in the artistic performances, coupled with some layouts of mass callisthenics, are unrelated to the Olympic spirit, it is necessary to regulate and enrich their contents. The sports elements and these of culture and art should proportionally be arranged on the basis of the principle of innovation so as to form a rational concept that sports elements are the core and symbols of culture and art are the foil.

\section{B. Innovating and Optimizing the Form and Structure of Opening Ceremonies}

Concerning the athletes admission the current layout should be broken. Instead, athletes try to show local culture by dressing native clothes or body languages standing for their culture, and even the athletes admission fits into the artistic performance and becomes an important part of the latter. In other words, athletes and spectators can be actors or actresses by simplifying related steps or changing the way of deciding all participants ahead of time, which will enhance people's expectation and share the Olympic spirit together. In addition, the traits of sport and the Olympics will be highlighted through the way of time or space or time-space.

\section{Limiting the Scale of Opening Ceremonies}

Because of the massive number of participants and the large expenditure, inclusive of the heavy environmental pollution, the scale of opening ceremonies should be limited properly. So, under the concept of the thrift Olympics, limiting rationally the number of participants and the expenditure of exceedingly packing should be the important steps for host countries in future.

\section{Conclusions}

The successive Olympics opening ceremonies have perfectly showed the human civilization and the international culture, but to some extent they have weakened and obscured the real sport spirit and the Olympic culture. It could root in people's cognition and attributes of sport, also relates to the sportsmen's moving and tragic feelings, namely, the modern sport is an elite culture and an education for gentlemen, all are pursuing for triumph and surpassing but end for being surpassed. It is different between the conceptional sport and the practical sport, the original value of education and culture must give way to the orientation of politics and economy nowadays; compared with the cruel course and final of competition, with athletes' short career and the long life, the solemn or joyful atmosphere of opening ceremonies is awful and sad. Concerning the development of Olympics opening ceremonies and sport, we should strive for a result that the former will return the sports culture itself and the latter will serve the human health and happiness.

\section{References}

[1] Huang Kuan-rou, Hu Xiao-ming, Li Zuo-hui, Xu Ai-mei, Zha Ping, and Zheng Dan-heng, "Charcteristics and innovation of the performances in the opening ceremonies of great national games and their influences on the society", Journal of Physical Education, vol.10, no.1, pp.15-17, Jan 2003.

[2] Niu Jing, and Ma Fa-chao, "Study on the history evolution that from ritual to performance of modern Olympic Games opening ceremonies",Journal of Sports and Science, vol.33, no.1, pp.60-64, Jan 2012.

[3] Wang Min,"On the beauty harmony of dance and music-on the problems of dance and music about the 29th Olympics and Paralympics",Journal of Beijing Dance Academy, no.3, pp.41-49, Sep 2009.

[4] Wang Ning, "A review and revelation about the Opening Ceremony of Beijing Olympic Games", Journal of Capital Institute of Physical Education, vol.21, no.1, pp.1-5, Jan 2009.

[5] Ren Hai, "Coubertin and Olympic Ceremony",China Sport Science and Technology, vol.37, no.3, Mar 2001.

[6] $\mathrm{Hu}$ He-ping, "Glorious world Chinese charms--on the artistic performance of the 2008 Beijing Olympics opening ceremony", Journal of Hunan University of Technology Social Science Edition, vol.15, no.1, pp.135-137, Feb 2010.

[7] Lu Yun-ting, "The vanguard arts under the eyesight of the internet-user-the popular comments about the 2008 Beijing Olympic ceremony opening conducted by Zhangyimou", Journal of Sports and Science, vol.31, no.1, pp.16-20, Jan 2010. 